\title{
Fundal Height
}

National Cancer Institute

\section{Source}

National Cancer Institute. Fundal Height. NCI Thesaurus. Code C154876.

A measurement of the distance between the pubic symphysis and the top of the palpable uterus. 